\title{
Ambient Educational Mini-games
}

\author{
Maria Asterios George Panagiotis Xenophon Margherita Constantine \\ Korozi $^{1}$ Leonidis $^{1}$ Margetis $^{1}$ Koutlemanis $^{1}$ Zabulis $^{1}$ Antona ${ }^{1}$ Stephanidis ${ }^{1,2}$ \\ ${ }^{1}$ Foundation of Research and Technology - Hellas (FORTH) \\ Institute of Computer Science, Heraklion, GR-70013, Greece \\ ${ }^{2}$ University of Crete, Department of Computer Science
}

$\{$ korozi, leonidis, margetis, koutle, zabulis, antona, cs\} @ ics.forth.gr

\begin{abstract}
This system paper describes two educational mini-games (a multiple-choice quiz and a geography-related game) that combine learning and ambient technology. Their innovative feature is that they offer physical interaction through printed cards on a tabletop setup, where a simple webcam monitors the table's surface and identifies the thrown cards. Following a brief discussion of ambient technology integration in the environment, the overall concept of these games is described and potential future improvements are outlined.
\end{abstract}

\section{Categories and Subject Descriptors}

K.3.1 [COMPUTERS AND EDUCATION]: Computer Uses in Education - Computer-assisted instruction (CAI)

\section{General Terms}

Experimentation, Human Factors.

\section{Keywords}

Ambient intelligence, educational games, physical interaction.

\section{INTRODUCTION}

The advancements of technology over the last few decades and the development of novel concepts to provide content-rich invisible computing applications have led to the emergence of the Ambient Intelligence (AmI) paradigm. AmI environments are sensitive and responsive to the presence of people and orchestrate the contained devices to support people in carrying out their everyday life activities. As devices get smaller, more connected and diffused in the environment, technology, including the user interface, disappears into the surroundings. As [5] highlights, new issues emerge concerning the interaction with computers embedded in everyday objects, as users cannot interact with invisible objects. However, real-world objects offer affordances that can be exploited towards building a hybrid world combining the best from the physical and the virtual worlds.

From a Human-Computer Interaction perspective, this results in the emergence of innovative interaction techniques, where users can communicate with the computer through familiar everyday objects. In such approaches technology is embedded in the

Permission to make digital or hard copies of all or part of this work for personal or classroom use is granted without fee provided that copies are not made or distributed for profit or commercial advantage and that copies bear this notice and the full citation on the first page. To copy otherwise, to republish, to post on servers or to redistribute to lists, requires prior specific permission and/or a fee.

AVI '12, May 21-25, 2012, Capri Island, Italy

Copyright (C) 2012 ACM 978-1-4503-1287-5/12/05... \$10.00 environment, and through various sensorial platforms (e.g., cameras, RFID sensors, etc.) monitors the environment, tracks the objects of interest, and translates in an unobtrusive manner their state (e.g., position, orientation, etc.) into system input.

\subsection{Education and AmI}

As ICT is already permeating education in many ways, AmI has a significant potential to impact the domain of education by increasing students' access to information, enriching the learning environment, allowing students' active learning and collaboration, and enhancing their motivation to learn ([1], [6]). Through a combination of technology, which is fascinating by its nature, and augmented interaction through physical objects, AmI technologies have the potential to enhance the classroom learning experience ([1], [3], [4]), as learners seem to be more willing to spend time on modern, technology-enabled, applications rather than traditional approaches.

\section{Games}

In the context of the above, two simple, yet indicative, educational tabletop mini-games were built that combine learning, entertainment and ambient intelligence, as a proof of concept that the transparent integration of AmI technologies in learning activities is feasible and cost-friendly. The developed games are: (i) a multiple choice quiz game and (ii) a geography-related game. Both games use physical cards as the primary interaction source.

The main computer orchestrates the game by monitoring the surface of a table for cards through a simple webcam and searching for potential matches (Figure 1). When a known card is thrown on the table, an image recognition algorithm finds the appropriate match. This algorithm is a modified (relaxed) version of the one described in [4] for the recognition of book pages. Subsequently, the game extracts, interprets and executes the corresponding command (e.g., select the answer of that card).

\subsection{Multiple choice Quiz}

The "Multiple choice Quiz", as its name indicates, is a regular multiple-choice game in which players are asked to select the best possible answer out of the choices from a list. Instead of selecting an answer or a category using a traditional input device (e.g., mouse, keyboard, touch screen, etc.), players perform the same actions (e.g., selecting an answer or picking a category of questions) by throwing a physical paper card on the table. The game does not take into consideration the card's orientation, although such information become available by the image processing sub-system.

Three different types of cards are contained in the deck: (i) cards that represent quiz categories and are used only for quiz selection, 
(ii) cards that represent answers and display the corresponding symbol (e.g., A, B, C, D), which can be used only during an active game session, and finally (iii) special-purpose cards (e.g., hints, back to menu, etc.) that can be used at any time.

The developed game contains three quiz categories, and each one contains ten multiple-choice questions with four possible answers. When the game starts, the player is able to pick a category by simply throwing a card on the table's surface within the camera's field of view. Upon recognition, the game initializes the list of questions with those of the selected category and the round starts.

During the game, the player is able either to throw an answer-card to choose the respective answer, or to throw a special-purpose card to ask for hints or go back to the game's menu. If an answercard is thrown, appropriate cues notify the player about the correctness of the answer, whereas when a special-purpose card is identified, either hints are displayed (e.g., elimination of two wrong answers) or the game menu is displayed. Finally, during an active game session the player can view the score achieved to that point and the remaining questions.

\subsection{Place the landmark}

"Place the landmark" was developed as a game that students could use to sharpen their geography skills. Cognitive psychologists claim that learning is an internal process and that the amount learned depends on the processing capacity and the effort spent during the learning process. Subsequently, memorizing the location of cities or historical monuments only through a schoolbook has little value, as students tend to easily forget such information. This game engages students in a collaborative activity where they learn through experience and will retain that knowledge for longer.

The player's objective is to identify and correctly place a number of landmarks at their right location on a map. For that to be achieved, the player has a deck of cards at his disposal, where each one represents a landmark (e.g., monument, sight, town etc.), and should be placed on the physical map mounted on the table. Alternatively, if ambient features are not desired, the game can be played as any other computer game using a mouse / touchscreen.

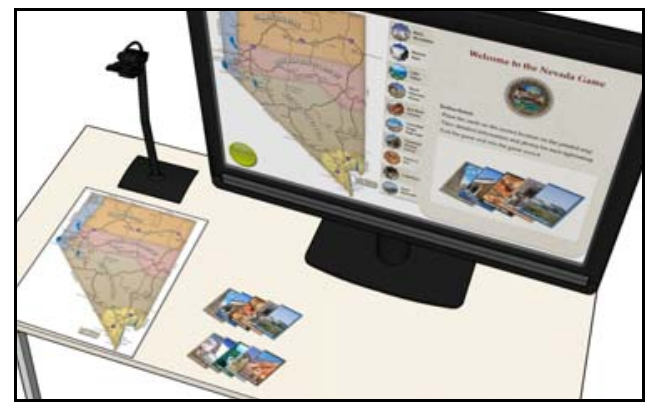

Figure 1: The physical setup of the system

The game preparation process includes, firstly, the physical installation of the map, where a printed map of the desired area is securely mounted on the table, within the camera's field of view-, and secondly, the game's calibration based on the physical boundaries of the map, to ensure the physical-to-digital translation of card's position. After installation, the game is ready to be played.

When the player picks a card and places it on the physical map, a virtual pin that represents the selected landmark is placed on the digital map at the same location. While the player moves the card trying to spot its correct location on the map, the virtual pin trails its movement on the virtual map. As soon as the player places the card over the correct location, the virtual pin is fixed at that point, and visual cues notify the player about his right choice.

The game provides two alternative types of assistance to the players. When a player throws a card on the map or selects a landmark, related content (e.g., multimedia and text) about that landmark is presented, while the player is able to browse through the provided information and explore the studied area in a more interactive and content rich way. On the other hand, if a player delays to identify the correct location of a landmark or keeps searching in the wrong direction, the appropriate part of the virtual map is highlighted indicating the whereabouts of the landmark.

\section{Conclusions and Future Work}

Currently, both games are installed in a portable and an ambient setup. The portable setup consists of a laptop and a portable webcam, whereas the ambient setup, following the concept of "disappearing computing", uses a wall-mounted large screen TV and a custom construction to hide the camera inside the wall.

Ongoing work aims to fully support the initial concept. Applications that can exploit the advanced features of the card recognition subsystem like orientation, or partial card identification, are under elaboration and will become available soon. Applications being developed include the "Alphabet and Spelling Tutor" that teach younger students how to spell, and the "Ambient Puzzle Solver" that assist simple puzzle solving.

Finally, following full implementation, a full scale evaluation experiment is being planned, aiming not only to assess the usability of the proposed environment, but its actual impact in the educational process as well.

\section{ACKNOWLEDGMENTS}

This work is supported by the FORTH-ICS internal RTD Programme 'Ambient Intelligence and Smart Environments'.

\section{REFERENCES}

[1] Antona, M., Leonidis, A., Margetis G., Korozi M., Ntoa S., and Stephanidis, C. 2011. A Student-Centric Intelligent Classroom. In Proceedings of AmI 2011. 248-252.

[2] Augusto, J. C. 2009. Ambient Intelligence: Opportunities and Consequences of its Use in Smart Classrooms. Volume 8 , Issue 2.

[3] Leonidis, A., Margetis, G., Antona, M., Stephanidis, C.: ClassMATE: Enabling Ambient Intelligence in the Classroom. World Academy of Science, Engineering and Technology, issue 66, pp. $594-598,2010$.

[4] Margetis, G., et al. 2012. Augmented interaction with physical books in an Ambient Intelligence learning environment. Multimedia Tools and Applications. January 2012, DOI: 10.1007/s11042-011-0976-x.

[5] Streitz, N. and Nixon, P. 2005. The Disappearing Computer. Communciatons of the ACM, 48 (3). pp. 32-35. ISSN 00010782.

[6] Xu P., Han. G. 2009. Towards Intelligent Interaction in Classroom. Universal Access in Human-Computer Interaction. 